\title{
An Increased Number of CD4+CD25+ Cells Induced by an Oral Administration of Lactobacillus plantarum NRIC0380 Are Involved in Antiallergic Activity
}

\author{
Tadashi Yoshida ${ }^{a}$ Wataru Fujiwara ${ }^{a}$ Mai Enomoto ${ }^{a}$ Sayuri Nakayama ${ }^{a}$ \\ Hiroshi Matsuda $^{b}$ Hisashi Sugiyama ${ }^{c}$ Manabu Shimojoh ${ }^{c}$ Sanae Okadad \\ Makoto Hattori ${ }^{a}$ \\ Departments of a Applied Biological Science and ${ }^{b}$ Veterinary Medicine, Tokyo University of Agriculture and \\ Technology, ${ }^{C} R \& D$ Center, Toyo Suisan Kaisha Ltd., and ${ }^{d}$ Culture Collection Center, Tokyo University of Agriculture, \\ Tokyo, Japan
}

\section{Key Words}

Cutaneous anaphylaxis reaction $\cdot$ Immunoglobulin E .

Lactic acid bacteria $\cdot$ Regulatory $T$ cells

\begin{abstract}
Background: Our previous study showed that an oral administration of Lactobacillus plantarum NRIC0380 inhibited immunoglobulin $\mathrm{E}$ (IgE) production in a murine model, and that orally administered NRIC0380 induced CD4+CD25+ Foxp3+ T, i.e. regulatory $T$ (Treg), cells in the spleen and Peyer's patch of mice. Although it has been reported that Treg cells might suppress the allergic symptoms, the involvement of the cells in the antiallergic activity of lactic acid bacteria has not been clearly demonstrated. We therefore examined in detail the antiallergic activity of Treg cells obtained from mice that had been fed NRIC0380. Methods: Treg cells were obtained from mice that had been fed NRIC0380. The T cellsuppressive effect of the cells was analyzed by coculturing the cells with splenocytes of $\beta$-lactoglobulin-immunized mice and $\beta$-lactoglobulin. The effects of the Treg cells on the IgE production and cutaneous anaphylaxis reaction were then analyzed by transferring the cells into another mouse. Results: The Treg cells obtained from the mice that had been
\end{abstract}

\section{KARGER}

E-Mail karger@karger.com

www.karger.com/iaa fed NRIC0380 showed similar T cell-suppressive activity to those cells obtained from the control mice. The Treg cells obtained from the mice fed NRIC0380 significantly inhibited the IgE production and active cutaneous anaphylaxis reaction when transferred into another mouse that was subsequently immunized with the antigen. Furthermore, the Treg cells also significantly suppressed the passive cutaneous anaphylaxis reaction when cotransferred with the IgE antibody into another mouse. Conclusions: The induction of Treg cells by the oral administration of NRIC 0380 would be involved in the antiallergic activity of NRIC0380.

(c) 2013 S. Karger AG, Basel

\section{Introduction}

The number of allergic patients worldwide has been seriously increasing in recent decades. The development of allergic diseases is influenced by many environmental factors, and the importance of a certain level of bacterial infection in young children decreasing the risk of contracting allergic diseases has been revealed [1]. It has also been shown that an oral administration of some lactic acid bacteria (LAB) could suppress allergic symptoms $[2$, 
3]. Although LAB have been reported as a modulator of the Th1/Th2 balance similar to some infectious bacteria in murine models $[4,5]$, it has not yet been clarified whether this is the only mechanism for the antiallergic activity of LAB.

It has been reported that people with a high percentage of CD4+Foxp3+, i.e. regulatory $\mathrm{T}$ (Treg), cells in their blood did not show any allergic symptoms even if the immunoglobulin E (IgE) level in the serum was high in comparison with that of allergic patients who had a lower proportion of CD4+Foxp3+ cells [6]. That report also suggested that Treg cells regulated the allergic symptoms through a mechanism independent of that for controlling the Th1/Th2 balance. Our previous study has shown that a strain of LAB, Lactobacillus plantarum NRIC0380, induced Treg cells by being orally administered to mice [7]. Several subsequent studies have also reported the induction of Treg cells by LAB $[8,9]$. These findings strongly suggest that NRIC0380 could demonstrate antiallergic activity by inducing Treg cells as well as by controlling the Th1/Th2 balance. However, the involvement of Treg cells in the antiallergic activity of LAB has not been previously examined.

The immune-regulating activity, including the antiallergic activity of $\mathrm{LAB}$, has been vigorously examined in many studies $[2-5,10,11]$, which found that it depended strongly on the strain, but not on the species of LAB [5]. Our study has also shown that several different strains of L. plantarum even had different immune-regulating activity [12]. NRIC0380 used in this study had been found to have strong IL-4-suppressive activity by an in vitro experiment, and then to have Treg-inducing activity by an in vivo experiment, as already mentioned. Our additional study has also revealed that NRIC0380 enhanced the retinal dehydrogenase activity of dendritic cells in the mesenteric lymph node, suggesting that this enhancement might have contributed to its Treg-inducing activity (manuscript in preparation). It is therefore expected that this strain could be applicable for use as an effective antiallergic food material. It is important for the safe and effective application of NRIC0380 to completely understand the mechanism for its antiallergic activity as well as to assess the activity in human clinical trials.

We examined here the antiallergic activity of Treg cells which had been obtained from mice fed NRIC0380 as well as its mechanism by active cutaneous anaphylaxis (ACA) and passive cutaneous anaphylaxis (PCA) tests. We also investigated the effect of those Treg cells on antigen-specific IgE production. Our results could make a major contribution to the practical application of NRIC0380 and other strains of LAB.

\section{Materials and Methods}

\section{Lactic Acid Bacteria}

L. plantarum NRIC0380 was obtained from the Culture Collection Center of Tokyo University of Agriculture (NRIC, Tokyo). NRIC0380 was cultured at $30^{\circ} \mathrm{C}$ in a half-strength MRS broth under anaerobic conditions with a mixed gas $\left(\mathrm{N}_{2}: \mathrm{H}_{2}: \mathrm{CO}_{2}=8: 1: 1\right)$ until the late exponential phase of growth. The half-strength MRS broth contained $10 \mathrm{~g} / \mathrm{l}$ glucose, $5 \mathrm{~g} / \mathrm{l}$ Bacto proteose peptone no. 3 (Becton Dickinson, Franklin Lakes, N.J., USA), 5 g/l Lab-Lemco powder (Oxoid, Cambridge, UK), $2.5 \mathrm{~g} / \mathrm{l}$ Becto yeast extract (Becton Dickinson), $0.5 \mathrm{~g} / \mathrm{l}$ Tween $80,1 \mathrm{~g} / 1 \mathrm{~K}_{2} \mathrm{HPO}_{4}, 2.5 \mathrm{~g} / \mathrm{l}$ sodium acetate $-3 \mathrm{H}_{2} \mathrm{O}, 1 \mathrm{~g} / \mathrm{l}$ triammonium citrate, $0.1 \mathrm{~g} / \mathrm{l} \mathrm{MgSO}_{4}-7 \mathrm{H}_{2} \mathrm{O}$ and $0.025 \mathrm{~g} / 1 \mathrm{MnSO}_{4}-4 \mathrm{H}_{2} \mathrm{O}$. The $\mathrm{pH}$ value was adjusted to 6.5 with $\mathrm{HCl}$. NRIC0380 was harvested by centrifugation, washed with sterilized deionized water, lyophilized and then stored at $-20^{\circ} \mathrm{C}$ until needed. The bacterial cells were used after autoclaving.

Mice

Six-week-old BALB/c mice were purchased from Clea Japan (Tokyo, Japan). All the mice were kept in accordance with the guidelines for the care and use of experimental animals of Tokyo University of Agriculture and Technology.

\section{Antigens and Antibodies}

Crude bovine $\beta$-lactoglobulin ( $\beta$-LG, genotype AA) was prepared from fresh milk from a Holstein cow according to the method of Armstrong et al. [13]. This crude $\beta$-LG was purified in a DEAE-Sepharose Fast Flow column $(3.0$ IDx $40 \mathrm{~cm}$; Amersham Pharmacia Biotech, Buckinghamshire, UK) by the method previously described [14], the degree of purity being confirmed by polyacrylamide gel electrophoresis (PAGE) performed by the method of Davis [15]. Bovine serum albumin (BSA) was purchased from Seikagaku Kogyo (Tokyo, Japan).

Biotin-labeled rat anti-mouse IgE (R35-118; BD Pharmingen, San Diego, Calif., USA) was used for ELISA. Fluorescein isothiocyanate (FITC)-labeled anti-mouse CD4 (GK1.5), biotinylated anti-mouse CD25 (PC61.5), streptavidine-labeled PE-Cy5 and a PE anti-mouse/rat Foxp3 staining set (FJK-16s) were purchased from eBioscience (San Diego, Calif., USA) and were used for flow cytometry.

\section{Oral Administration of NRIC0380}

The BALB/c mice were administered NRIC 0380 orally, 3 times a week to give a total number of 5 or 13 feeds, depending on the experiments. NRIC0380 was dissolved in PBS at 1 or $5 \mathrm{mg} / \mathrm{ml}$ (approximately 8 billion bacterial cells in $1 \mathrm{mg}$ of sample), and $200 \mu \mathrm{l}$ was fed to each mouse by a feeding needle. BALB/c mice administered with PBS were used as a control. These mice were immunized with $100 \mu \mathrm{g}$ of $\beta$-LG dissolved in saline mixed with an equal amount of an alum adjuvant $(20 \mathrm{mg} / \mathrm{ml})$ after the secondary feeding.

\section{Purification of the Treg Cells}

$\mathrm{CD} 4+\mathrm{CD} 25+$ Treg cells were isolated from the spleen of $\mathrm{BALB} / \mathrm{c}$ mice that had received NRIC0380 ( $1 \mathrm{mg} /$ feed) 5 times by oral administration and immunized with $\beta$-LG by using a mouse CD4+CD25+ Treg cell isolation kit (Miltenyi Biotec, Bergish Gladbach, Germany). This procedure was carried out 1-3 days after the fifth administration of NRIC0380. In the previous study, we reported that the ratio of Treg cells increased after administering 
NRIC0380 13 times. We then performed a time-course analysis for inducing Treg cells by orally administered NRIC0380 and found that the ratio of Treg cells in the mice given NRIC0380 had increased considerably even after the 5th administration (data not shown); we therefore decided to obtain Treg cells from the mice after this. We also checked the effect on the Treg cells by feeding $0.2 \mathrm{mg} /$ feed of NRIC0380, but did not observe any significant increase of Treg cells in the mice. We therefore decided to obtain Treg cells from the mice fed $1 \mathrm{mg}$ of NRIC0380 5 times.

\section{Cell Culture}

To evaluate the suppressive effect of the Treg cells on the antigen-specific proliferation of naïve splenocytes, spleen cells $(1.5 \times$ $10^{6}$ cells $/ \mathrm{ml}$ ) from the mice that had been immunized with $\beta$-LG were incubated in a 96-well plate with $\beta$-LG $(200 \mu \mathrm{g} / \mathrm{ml})$ and the Treg cells $\left(0,3.8 \times 10^{5}, 7.5 \times 10^{5}\right.$ and $1.5 \times 10^{6}$ cells $\left./ \mathrm{ml}\right)$ in an RPMI1640 medium (Nissui Pharmaceuticals, Tokyo, Japan) containing $1 \%$ normal mouse serum that had previously been obtained from normal BALB/c mice. Two days after stimulation, the proliferation of the cells in each well was measured in accordance with the protocol for cell proliferation ELISA of the BrdU kit (Roche Diagnostics, Basel, Switzerland).

\section{Transfer of the Treg Cells}

To evaluate the antiallergic effect of the Treg cells on the antigen-specific IgE production or cutaneous anaphylaxis reaction, Treg cells isolated from the mice that had had NRIC0380 administered orally 5 times and had been immunized with $\beta$-LG were suspended in PBS and transferred (i.v.) into BALB/c mice (5-10 mice/group). The number of cells transferred was $1-3 \times 10^{6}$ cells/ head depending on the experiment, because the number of Treg cells obtained from the donor mice varied. The mice that had been treated with PBS were used as the control.

\section{Preparation of the Serum}

The mice that had been treated with the Treg cells were subsequently immunized with $\beta$-LG on the day after cell transfer. The serum was prepared from these mice 2 weeks after the immunization for use in the $\operatorname{IgE}$ assay.

\section{ELISA}

The amount of the $\beta$-LG-specific IgE antibodies in the serum was detected by ELISA. In brief, a Maxisorp 96-well plate (Nunc, Roskilde, Denmark) was coated overnight at $4^{\circ} \mathrm{C}$ with $\beta$-LG. Each well was blocked by $1 \%$ BSA after washing. After further washing, a culture supernatant and standard were added to the wells. After another washing, the bound antibody was detected with biotin-labeled rat anti-mouse IgE (R35-118, BD Pharmingen), before being incubated with alkaline phosphatase-streptavidine (Zymed, San Francisco, Calif., USA). After a final washing, a $p$-nitrophenyl-phosphate substrate was added, and the absorbance was measured at $405 \mathrm{~nm}$. The titer of $\beta$-LG-specific IgE in the sample serum was calculated relative to that of $\beta$-LG-specific IgE in the standard serum that had previously been obtained from the $\beta$-LG-immunized mice. The results were standardized against the value for the control group.

\section{Flow Cytometry}

To evaluate the ratio of CD4+CD25+Foxp3+ cells/CD4+ cells, spleen cells from the mice that had been treated with the Treg cells and immunized with $\beta$-LG were stained with FITC anti-mouse
CD4, biotinylated anti-mouse CD25 and streptavidine-labeled PECy5. Foxp 3 was also stained with a PE anti-mouse/rat Foxp3 staining set. The cells were analyzed with an Epics Elite ESP instrument (Coulter, Miami, Fla., USA), this analysis being carried out 6 days after transferring the Treg cells.

\section{Cutaneous Anaphylaxis Test}

The effect of orally administered NRIC0380 on the cutaneous anaphylaxis reaction was tested by using the mice that had been fed 13 times with NRIC0380 (0.2 mg/feed) and immunized with $\beta$-LG. These mice were i.v. injected with $50 \mu \mathrm{l}$ of a $1 \%$ Evans blue (dye) saline solution, before eliciting the cutaneous anaphylaxis reaction on the dorsal region of the mice by injecting $30 \mu \mathrm{l}$ of an antigen saline solution ( $\beta$-LG, $10 \mu \mathrm{g} / \mathrm{ml})$. The mice were sacrificed 30 min after the $\beta$-LG challenge, and the dorsal skin was removed for measuring the extravasated dye in the skin. The densitometric method was used to evaluate the size of each spot, the results being standardized against the value for the control group.

The effect of Treg cells on the ACA reaction was tested by using the mice that had been treated with Treg cells. These mice were immunized with $\beta$-LG on the day after cell transfer, and the cutaneous anaphylaxis test already described was performed 18 days after the immunization.

The effect of Treg cells on the PCA reaction was also tested by using the mice that had been treated with the Treg cells. The anti$\beta$-LG antiserum was simultaneously transferred to these mice, and then the cutaneous anaphylaxis test was performed the next day. The anti- $\beta$-LG antiserum used in this study was prepared beforehand from the mice that had been immunized with $\beta$-LG.

\section{Statistics}

Differences between the control and NRIC0380-fed or Tregtreated groups were evaluated by the Student t test and were considered significant at $\mathrm{p}<0.05$.

\section{Results}

\section{Treg Cells Obtained from the Mice Fed with}

NRIC0380 Showed Similar Suppressive Activity to

That of the Control Treg Cells

It has been reported that the suppressive activity of Treg cells could be affected by several factors. Although our previous study demonstrated that orally administered NRIC0380 increased the ratio of Treg cells, this activity of NRIC0380 might not have been able to contribute its antiallergic activity if the Treg cells induced by the bacteria alone had had a lower regulatory activity than the cells from the control mice. We therefore examined the suppressive activity of Treg cells obtained from the mice fed with NRIC0380 for comparison with those from the control mice.

Figure 1 shows that the cell proliferation of $\beta$-LGspecific splenocytes (the responders) was significantly inhibited by adding the Treg cells (the modulators). The level of inhibition became stronger with increasing 
number of Treg cells. There was no significant difference between the suppressive activity of Treg cells obtained from the mice with or without NRIC0380 administration.

Treg Cells Obtained from the Mice That Had Been Fed with NRIC0380 Inhibited IgE Production

We then examined the effect on IgE production of Treg cells obtained from the mice that had been fed with NRIC0380. We first confirmed the proportion of Treg cells in the spleen of the mice after transferring the Treg cells. Table 1 shows that the proportion of Treg cells changed from 13.6 to $14.2 \%$ by transferring the Treg cells. Our previous study showed that orally administering NRIC0380 to mice increased the ratio of Treg cells in the spleen from 6.7 to $10.2 \%$. Although the spontaneous ratio of Treg cells in that study was a little different, our current results indicate that the increased level of Treg cells resulting from the transfer could be reproducible by eating NRIC0380, suggesting that the number of Treg cells transferred into the recipient mice was appropriate for analyzing the antiallergic effect of the cells as one mechanism for the antiallergic activity of NRIC0380.

Figure 2 shows that the transfer of Treg cells significantly inhibited antigen-induced IgE production, suggesting that the increased number of Treg cells induced by NRIC0380 could contribute to suppressing allergic diseases by inhibiting IgE production.

Treg Cells Obtained from the Mice That Had Been Fed with NRIC0380 Inhibited the Cutaneous Anaphylaxis Reaction

Our results suggested that NRIC0380 could act as an antiallergic material by inducing Treg cells. We therefore directly examined the effect of Treg cells on the allergic symptoms. We first confirmed whether the oral administration of NRIC 0380 could actually inhibit these symptoms. Figure 3 shows that the mice fed with NRIC0380 demonstrated a lower level of the cutaneous anaphylaxis reaction than the control mice after immunizing with the antigen. Similar activity of LAB has already been reported by Shah et al. [16] for another strain of LAB.

We then examined the contribution of the Treg cells induced by NRIC0380 to the anticutaneous anaphylaxis activity of NRIC0380. Figure 4 shows that the mice treated with Treg cells taken from the mice fed with NRIC0380 demonstrated a lower level of the cutaneous anaphylaxis reaction than the control mice after immunizing with the antigen. We also checked that transfer-

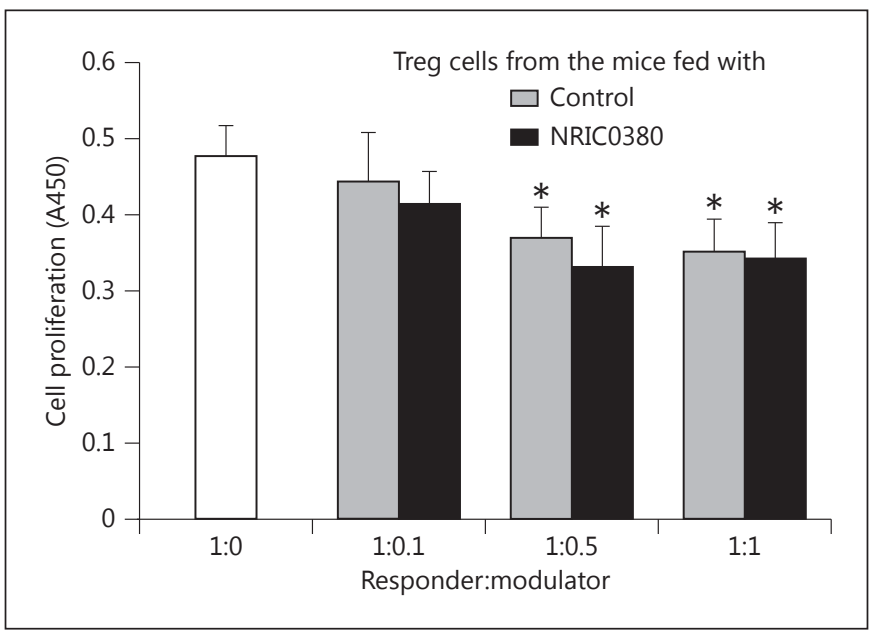

Fig. 1. Effect of orally administered NRIC0380 on the activity of Treg cells. Splenocytes (responders) of $\beta$-LG-immunized BALB/c mice were cultured in a 96-well plate with $\beta$-LG and Treg cells (modulators) obtained from mice that had been fed NRIC0380 5 times or from the control (PBS-administered) mice. The proliferative response of each well was analyzed on day 2 of the culture by BrdU ELISA. The results are representative of 2 independent experiments. * Significant difference compared with the response of wells cultured without Treg cells $(\mathrm{p}<0.05)$.

Table 1. Ratio of Treg cells in the spleen of mice to which Treg cells had been transferred

Treatment CD $4+$ CD25+Foxp3+ cells/ CD4+ cells, \%

Control (untreated)

$13.55 \pm 0.46$

Treg transferred

$14.23 \pm 1.65$

Treg cells obtained from the mice that had been fed 5 times with NRIC0380 were transferred to BALB/c mice. The mice were immunized with $\beta$-LG on the day after transfer. The ratio of Treg cells in the spleen of the mice was analyzed by flow cytometry 5 days after immunization. The results are representative of 2 independent experiments.

ring CD4+CD25- T cells instead of CD4+CD25+ Treg cells had no effect on the cutaneous anaphylaxis reaction, indicating that this inhibition was based on the activity peculiar to Treg cells (data not shown). Furthermore, the mice that had been treated with the Treg cells and anti- $\beta$-LG antiserum showed a lower level of the cutaneous anaphylaxis reaction than the control mice (fig. 5), indicating that Treg cells induced by orally ad- 


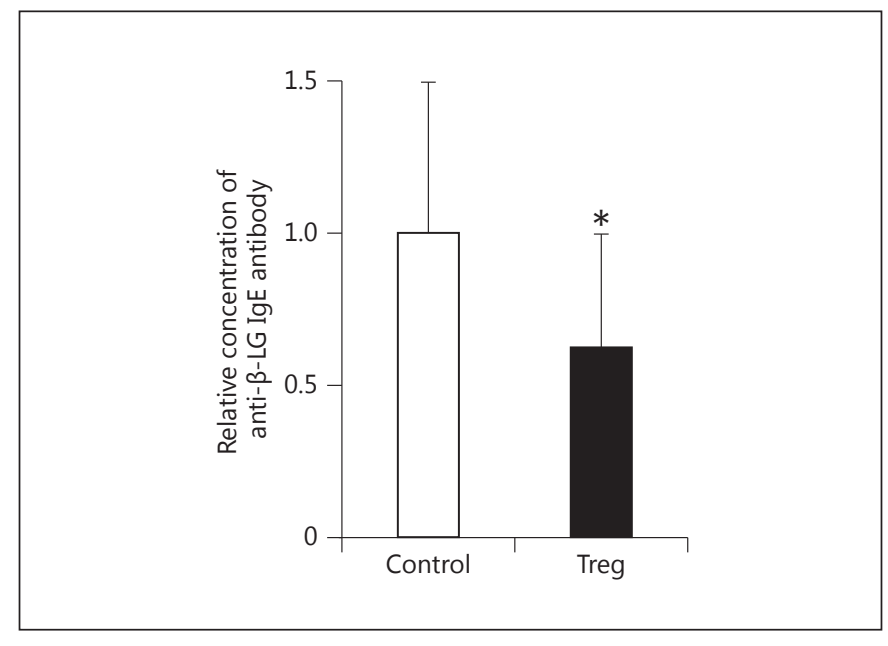

Fig. 2. Inhibition of IgE production by transferring Treg cells. Treg cells obtained from the mice that had been fed 5 times with NRIC0380 were transferred to BALB/c mice. These mice were immunized with $\beta$-LG on the day after transfer. The level of the $\beta$-LGspecific IgE antibody in the sera of the mice was measured 2 weeks after immunization. Similar results were obtained from 3 independent experiments and are shown as a total of all 3 experiments. * Significant difference compared with the control without transferring Treg cells, $\mathrm{p}<0.05$.

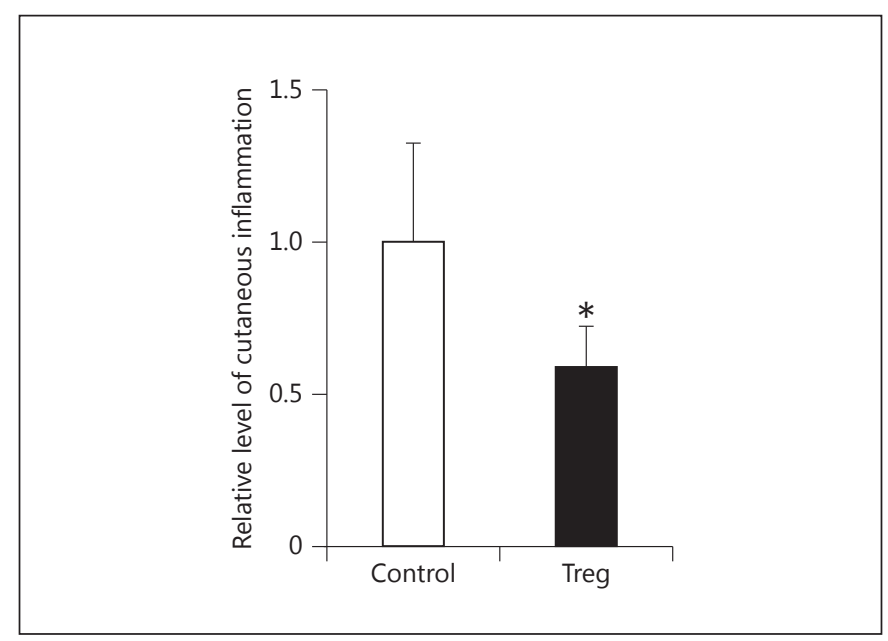

Fig. 4. Inhibition of the ACA reaction by transferring Treg cells. Treg cells obtained from the mice that had been fed 5 times with NRIC0380 were transferred to BALB/c mice. These mice were immunized with $\beta$-LG the next day. Eighteen days after the immunization, the level of the ACA reaction was evaluated as described in figure 3 . The results are representative of 3 independent experiments. * Significant difference compared with the control without transferring Treg cells, $\mathrm{p}<0.05$.

Antiallergic Activity of Treg Cells Induced by LAB

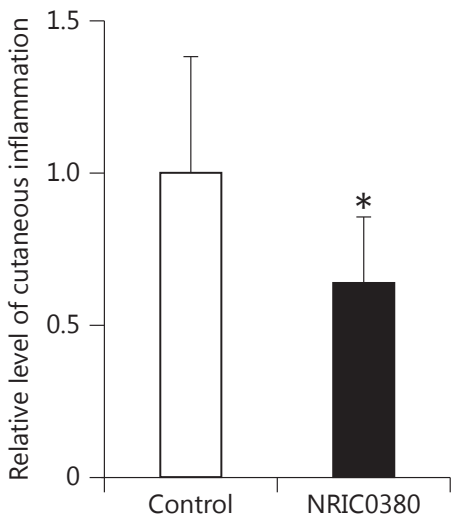

Fig. 3. Inhibition of the ACA reaction by orally administered NRIC0380. BALB/c mice were fed 13 times with NRIC0380. These mice were immunized with $\beta$-LG before the second feeding. Four weeks after immunization, the mice were i.v. injected with $50 \mu \mathrm{l}$ of a $1 \%$ Evans blue saline solution, before eliciting the ACA reaction on the dorsal region of the mice by injecting $30 \mu \mathrm{l}$ of an antigen saline solution. The mice were sacrificed $30 \mathrm{~min}$ after the $\beta-\mathrm{LG}$ challenge, and the dorsal skin was removed for measuring the extravasated dye in the skin. The densitometric method was used to evaluate the size of each spot. The results are representative of 3 independent experiments. ${ }^{*}$ Significant difference compared with the control without feeding NRIC0380, $\mathrm{p}<0.05$.

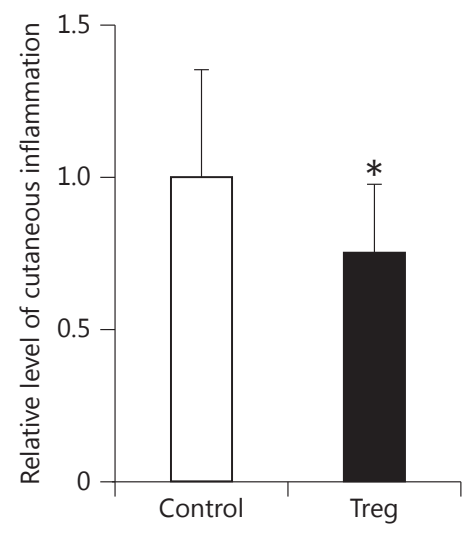

Fig. 5. Inhibition of the PCA reaction by transferring Treg cells. Treg cells obtained from the mice that had been fed 5 times with NRIC0380 were transferred to BALB/c mice. The anti- $\beta$-LG antiserum was simultaneously transferred to these mice. The level of the cutaneous anaphylaxis reaction was evaluated the next day as described in figure 3. Similar results were obtained from 2 independent experiments and are shown as a total of these. * Significant difference compared with the control without transferring Treg cells, $\mathrm{p}<0.05$.

Int Arch Allergy Immunol 2013;162:283-289 
ministering NRIC0380 would inhibit the allergic symptoms in two distinct ways, one being mediated by IgE inhibition and the other by directly inhibiting the allergic reaction.

\section{Discussion}

The objectives of this study were to determine the contribution of the increased number of Treg cells induced by orally administering NRIC0380 to the antiallergic activity of NRIC0380, and the mechanism for the antiallergic activity of the Treg cells. Our results clearly demonstrate that NRIC0380 inhibited the allergic symptoms by inducing Treg cells. The increased number of Treg cells induced by orally administering NRIC0380 would have contributed to inhibiting the allergic symptoms via two distinct mechanisms, one being mediated by inhibiting the IgE production and the other by directly inhibiting the anaphylaxis reaction. This study is the first to directly demonstrate the contribution of the Treg-inducing ability of LAB to its antiallergic activity. Our findings will be useful for the safe and effective application of NRIC0380 and/or other strains of LAB to prevent and treat allergic diseases.

The results of three experimental methods show that Treg cells obtained from the mice that had been fed with NRIC0380 inhibited the allergic responses. The results from ACA and the IgE-inhibiting test indicate that the Treg cells might have inhibited the allergic skin reaction by suppressing IgE production. Although the mechanism for this action has still to be elucidated, this might have been mediated by the inhibition of $\mathrm{T}$ cell responses and/ or of $\mathrm{B}$ cell activation. There have been several studies reporting the influence of Treg cells on B cell class-switching and antibody production $[17,18]$. On the other hand, the result from the PCA test clearly shows that the Treg cells also inhibited the allergic reactions occurring after IgE production, suggesting that Treg cells inhibited degranulation of the mast cells. It has been reported in a previous study that the interaction between Treg cells and mast cells via OX40-OX40L would inhibit the degranulation of mast cells induced by the signals from FceRI [19]. IL-10 and TGF- $\beta$ produced by Treg cells might also be involved in the inhibition of mast cell degranulation [17]. Indeed, subjects having a higher proportion of Treg cells in their blood did not show any allergic symptoms even if they had a similar IgE level to that of allergic patients [6]. This evidence indicates that the proportion of Treg cells would be really important to control allergic symptoms, and that the increased number of Treg cells induced by NRIC0380 might play an important role in the antiallergic activity of NRIC0380. Another strain of LAB was reported in the previous study to induce Treg cells and inhibit IgE production, ACA and PCA $[9,16]$. This study strongly supports those results and suggests that the suppression of IgE, ACA and PCA shown in that report would be mediated by Treg cells induced by the strain of $\mathrm{LAB}$.

It has been proposed that $\mathrm{LAB}$ suppressed allergic diseases by regulating the Th1/Th2 balance $[4,5]$. Several strains of LAB, including NRIC0380, have been shown to possess Th1-inducing activity $[4,5,7]$. Recent studies have revealed that bacteria, including $\mathrm{LAB}$, were recognized by immune cells via some pattern-recognizing receptors $[20,21]$. Toll-like receptors (TLRs) are the most well-known family of pattern-recognizing receptors, and some strains of $\mathrm{LAB}$ have been shown to be recognized by TLR2 and TLR4 [22, 23]. Immune cells produce cytokines like IL-12 after recognizing LAB, leading to Th1 skewing. However, it might take a long time to correct the Th1/Th2 balance in allergic patients by taking LAB, because it is difficult to induce the redifferentiation of already-differentiated Th2 cells into Th1 cells. In addition, there are already many IgE-producing plasma cells in a patient, suggesting that it is difficult to inhibit allergic symptoms by only correcting the Th1/Th2 balance. On the other hand, Treg cells would suppress the response of already differentiated Th2 cells and the degranulation of mast cells, suggesting that the induction of Treg cells by antiallergic food might provide a good treatment for allergic symptoms in the short term. NRIC0380 demonstrated both activities, leading us to expect that NRIC0380 would improve allergic diseases by two distinct mechanisms.

We transferred $1-3 \times 10^{6}$ Treg cells into each recipient mouse. We did not observe any significant increase of the Treg ratio in the spleen of recipient mice after the transfer. It has been reported in previous studies, including ours, that an oral administration of LAB increased the ratio of Treg cells by about 1.5 times compared with the control group $[8,9]$. We consider from these results that the increased Treg ratio occurring in our experimental model could be reconstituted by the oral administration of $\mathrm{LAB}$, indicating that the antiallergic activity observed in the mice to which the Treg cells were transferred, that had been obtained from the mice that had been fed NRIC0380, would also act in those mice that had been fed NRIC0380.

There is a report showing that the activity of Treg cells obtained from Graves' disease patients was lower than that from healthy subjects, and was improved by being 
treated with dexamethasone [24]. This evidence indicates that the activity of Treg cells could be changed by some factors. However, no difference was apparent in the immunosuppressive activity between Treg cells from the mice fed NRIC0380 and the control mice. This result suggests that NRIC0380 would show antiallergic activity by increasing the number of Treg cells and not the activity of each cell.

The results of this study include several new findings about the antiallergic activity of LAB. It is proposed that NRIC0380 would be a useful food material with at least two distinct antiallergic activities.

\section{References}

1 Strachan DP: Hay fever, hygiene, and household size. BMJ 1989;299:1259-1260.

-2 Ishida Y, Nakamura F, Kanzato H, Sawada D, Yamamoto N, Kagata H, Oh-Ida M, Takeuchi $\mathrm{H}$, Fujiwara S: Effect of milk fermented with Lactobacillus acidophilus strain L-92 on symptoms of Japanese cedar pollen allergy: a randomized placebo-controlled trial. Biosci Biotechnol Biochem 2005;69:1652-1660.

3 Wakabayashi H, Nariai C, Takemura F, Nakao W, Fujiwara D: Dietary supplementation with lactic acid bacteria attenuates the development of atopic-dermatitis-like skin lesions in NC/Nga mice in a strain-dependent manner. Int Arch Allergy Immunol 2008;145: 141-151.

-4 Shida K, Makino K, Morishita A, Takamizawa K, Hachimura S, Ametani A, Sato T, Kumagai Y, Habu S, Kaminogawa S: Lactobacillus casei inhibits antigen-induced $\operatorname{IgE}$ secretion through regulation of cytokine production in murine splenocyte cultures. Int Arch Allergy Immunol 1998;115:278-287.

5 Fujiwara D, Inoue S, Wakabayashi H, Fujii T: The anti-allergic effects of lactic acid bacteria are strain-dependent and mediated by effects on both Th1/Th2 cytokine expression and balance. Int Arch Allergy Immunol 2004;135 205-215.

6 Orihara K, Narita M, Tobe T, Akasawa A, Ohya Y, Matsumoto K, Saito H: Circulating Foxp3+CD4+ cell numbers in atopic patients and healthy control subjects. J Allergy Clin Immunol 2007;120:960-962.

7 Enomoto M, Noguchi S, Hattori M, Sugiyama H, Suzuki Y, Hanaoka A, Okada S, Yoshida T: Oral administration of Lactobacillus plantarum NRIC0380 suppresses IgE production and induces CD4+CD25+Foxp3+ cells in vivo. Biosci Biotechnol Biochem 2009;73: 457-460. $\checkmark 8$ Lyons A, O'Mahony D, O’Brien F, MacSharry J, Sheil B, Ceddia M, Russell WM, Forsythe P, Bienenstock J, Kiely B, Shanahan F, O’Mahony L: Bacterial strain-specific induction of Foxp3+ T regulatory cells is protective in murine allergy models. Clin Exp Allergy 2010;40: 811-819.

$\checkmark$ Shah MM, Saio M, Yamashita H, Tanaka H, Takami T, Ezaki T, Inagaki N: Lactobacillus acidophilus strain L-92 induces CD4+CD25+Foxp3+ regulatory $\mathrm{T}$ cells and suppresses allergic contact dermatitis. Biol Pharm Bull 2012;35:612-616.

10 Cain AM, Karpa KD: Clinical utility of probiotics in inflammatory bowel disease. Altern Ther Health Med 2011;17:72-79.

11 Mortaz E, Adcock IM, Folkerts G, Barnes PJ, Paul Vos A, Garssen J: Probiotics in the management of lung diseases. Mediators Inflamm 2013;2013:751068.

-12 Noguchi S, Hattori M, Sugiyama H, Hanaoka A, Okada S, Yoshida T: Lactobacillus plantarum NRIC1832 enhances IL-10 production from CD4+ T cells in vitro. Biosci Biotechnol Biochem 2012;76:1925-1931.

13 Armstrong JM, McKenzie HA, Sawyer WH: On the fractionation of $\beta$-lactoglobulin and $\alpha$-lactalbumin. Biochimica et Biophysica Acta 1967;147:60-72.

14 Hattori M, Nagasawa K, Ametani A, Kaminogawa S, Takahashi K: Functional changes in $\beta$-lactoglobulin by conjugation with carboxymethyl dextran. J Agric Food Chem 1994;42:2120-2125.

15 Davis BJ: Disc electrophoresis-II: method and application to human serum proteins. Ann NY Acad Sci 1964;121:404-427.

16 Shah MM, Miyamoto Y, Yamada Y, Yamashita $\mathrm{H}$, Tanaka H, Ezaki T, Nagai H, Inagaki N: Orally supplemented Lactobacillus acidophilus strain L-92 inhibits passive and active cutaneous anaphylaxis as well as 2,4-dinitrofluorobenzene and mite fecal antigen induced atopic dermatitis-like skin lesions in mice. Microbiol Immunol 2010;54:523-533.
17 Ozdemir C, Akdisw M, Akdisw CA: T regulatory cells and their counterparts: masters of immune regulation. Clin Exp Allergy 2009; 39:626-639.

18 Jang E, Cho WS, Cho ML, Park HJ, Oh HJ, Kang SM, Paik DJ, Youn J: Foxp3+ regulatory $\mathrm{T}$ cells control humoral autoimmunity by suppressing the development of long-lived plasma cells. J Immunol 2011;186:1546-1553.

19 Gri G, Piconese S, Frossi B, Manfroi V, Merluzzi S, Tripodo C, Viola A, Odom S, Rivera J, Colombo MP, Pucillo CE: CD4+CD25+ regulatory $\mathrm{T}$ cells suppress mast cell degranulation and allergic responses through OX40-OX40L interaction. Immunity 2008;29:771-781.

20 Diebold SS: Activation of dendritic cells by Toll-like receptors and C-type lectins. Hand Exp Pharmacol 2009;188:3-30.

21 Rizzello V, Bonaccorsi I, Dongarrà ML, Fink LN, Ferlazzo G: Role of natural killer and dendritic cell crosstalk in immunomodulation by commensal bacteria probiotics. J Biomed Biotechnol 2011;2011:473097.

22 Kaji R, Kiyoshima-Shibata J, Nagaoka M, Nanno M, Shida K: Bacterial teichoic acids reverse predominant IL-12 production induced by certain Lactobacillus strains into predominant IL-10 production via TLR2-dependent ERK activation in macrophages. J Immunol 2010;184:3505-3513.

23 Ichikawa S, Fujii R, Fujiwara D, Komiyama Y, Kaisho T, Sakaguchi M, Konishi Y: MyD88 but not TLR2, 4 or 9 is essential for IL-12 induction by lactic acid bacteria. Biosci Biotechnol Biochem 2007;71:3026-3032.

$24 \mathrm{Hu}$ Y, Tian W, Zhang LL, Liu H, Yin GP, He BS, Mao XM: Function of regulatory T-cells improved by dexamethasone in Graves' disease. Eur J Endocrinol 2012;166:641-646. 